\title{
Secondary aortoenteric fistula possibly associated with continuous physical stimulation: a case report and review of the literature
}

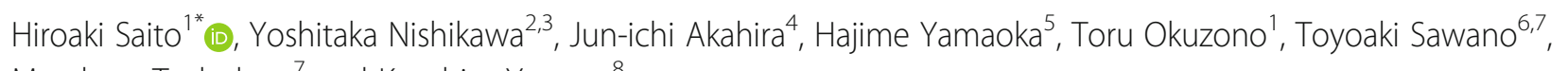
Masaharu Tsubokura ${ }^{7}$ and Kazuhiro Yamaya ${ }^{8}$

\begin{abstract}
Background: Secondary aortoenteric fistula is a rare but fatal complication after reconstructive surgery for an aortic aneurysm characterized by abdominal pain, fever, hematochezia, and hematemesis, and the mortality rate is high. It has been suggested that it arises due to either continuous physical stimulation or prosthesis infection during primary surgery. We describe an aortoenteric fistula following reconstructive surgery for an abdominal aortic aneurysm together with postmortem pathological findings.

Case presentation: A 59-year-old Japanese man who had undergone reconstructive surgery for an abdominal aortic aneurysm 20 months earlier presented with the chief complaint of hematochezia and malaise. Esophagogastroduodenoscopy and total colonoscopy revealed only colon diverticula with no bleeding. Contrast-enhanced computed tomography revealed gas within the aneurysm sac and adhesion between the replaced aortic graft and intestinal tract, suggesting a graft infection. After 18 days of antibiotic treatment, he suddenly went into a state of shock, with massive fresh bloody stool and hematemesis, followed by cardiac arrest. An autopsy revealed communication between the artery and the ileum through an ulcerative fistula at the suture line between the left aortic graft branch and the left common iliac artery. Pathological analysis revealed tight adherence between the arterial and intestinal walls, but no marked sign of infection around the fistula, suggesting that the fistula had arisen due to physical stimuli.

Conclusions: Pathological analysis suggested that the present secondary aortoenteric fistula arose due to physical stimuli. This reaffirms the importance of keeping reconstructed aortas isolated from the intestine after abdominal aortic aneurysm surgery.
\end{abstract}

Keywords: Aortoenteric fistula, Abdominal aortic aneurysm, Intestinal bleeding, Herald bleeding

\section{Background}

A secondary aortoenteric fistula (SAEF) is an abnormal connection between the aorta and gastrointestinal tract resulting from reconstructive surgery for an abdominal aortic aneurysm (AAA), including open repair surgery and endovascular treatment. Although rare (incidence rate, 1.6 to $4 \%)[1-4]$, it is life-threatening and has a

\footnotetext{
* Correspondence: h.saito0515@gmail.com

${ }^{1}$ Department of Gastroenterology, Sendai Kousei Hospital, Sendai, Miyagi, Japan

Full list of author information is available at the end of the article
}

high mortality rate (24 to $45.8 \%$ ) [5-7]. Elucidating the clinical features and improving the diagnosis of SAEF would therefore be valuable.

The mechanism underlying the pathological development of SAEFs remains unknown. Two hypotheses have been postulated. One suggests an origin in continuous stimulation due to aortic pulsation directly affecting the walls of the intestinal tract and arteries [2, 4, 7-9]. This theory is supported by the fact that most SAEFs involve the third or fourth portion of the duodenum which are compressed between the superior mesenteric artery and

(c) The Author(s). 2019 Open Access This article is distributed under the terms of the Creative Commons Attribution 4.0 International License (http://creativecommons.org/licenses/by/4.0/), which permits unrestricted use, distribution, and 
abdominal aorta in the retroperitoneal space [5]. The other argues an origin in a local inflammatory response due to prosthesis infection during primary surgery $[5,7-$ 10]. Several species of bacteria not usually identified in the intestine, such as Staphylococcus, have been detected in aortic prostheses in cases of SAEF, which supports this hypothesis.

Here, we describe an aortoenteric fistula following reconstructive surgery for an AAA and discuss the implications of postmortem pathological analysis. We believe the findings further our understanding of the underlying mechanism of SAEFs, which could be useful in deciding a preventive strategy.

Written informed consent was obtained from the patient's family for publication of this case.

\section{Case presentation}

A 59-year-old Japanese man presented to our hospital with the chief complaint of hematochezia and malaise. On the day of admission and 10 days earlier, he had produced a fresh bloody stool. He had undergone open surgery with a bifurcated graft for an AAA 20 months earlier. The course was uneventful, with no remarkable findings on computed tomography (CT) at 6 and 18 months postoperatively. An abdominal examination at our hospital revealed nothing remarkable and no tenderness. His blood pressure was $122 / 75 \mathrm{mmHg}$; heart rate, $86 /$ minute; body temperature, $36.6{ }^{\circ} \mathrm{C}$; breathing, 16 per minute; and hemoglobin level, $9.0 \mathrm{~g} / \mathrm{dL}$.

Esophagogastroduodenoscopy and total colonoscopy revealed only colon diverticula and no bleeding. Contrast-enhanced CT revealed gas within the aneurysm sac (Fig. 1a, b, yellow arrowhead) and adhesion between the graft and intestinal tract in three areas: the ileum had attached to the anastomosis between the left branch of the graft and left common iliac artery (Fig. 1a, yellow circle); the jejunum to the middle of the graft body; and the duodenum to the anastomosis between the aorta and the proximal graft. Enterococcus faecium was isolated from blood culture, suggesting communication between the intestinal tract and aorta at the attached sites, possibly due to infection of the graft. His vital signs were stable, so surgery was scheduled to take place after antibiotic treatment. After admission, he produced another fresh bloody stool, but bleeding ceased immediately. At 18 days after the second fresh bloody stool, however, he suddenly went into a state of shock, with massive fresh bloody stool and hematemesis, followed by cardiac arrest. Despite intensive cardiopulmonary resuscitation, he died from hemorrhagic shock.

An autopsy performed with written consent from the family revealed an ulcerative fistula in the distal ileum that adhered to the anastomosis between the left branch of the graft and the left common iliac artery (Fig. 2a), with a small hole at the aortic anastomosis (Fig. 2b). Arterial structure was destroyed at the anastomotic site. There was fibrous thickening of the arterial wall (Fig. 3a, b) and the external elastic lamina had disappeared. The serosa of the small intestine and adventitia of the artery were firmly adhered (Fig. 3c, d). There was no marked sign of infection, such as inflammatory cells or phagocytosis, even around the fistula.

\section{Discussion}

SAEFs are a rare but life-threatening complication after aortic aneurysm reconstruction $[1-3,11]$. Despite the importance of establishing the underlying mechanism of fistula formation, their etiology remains unclear. It has been suggested that either chronic infection of the graft or physical stimulation, such as from aortic pulsation pressure, contributes to their formation, which is usually determined based solely on the clinical course or surgical findings [12-19]. To the best of our knowledge, only 25 case reports on SAEFs have been published (see Table 1). Of these, only six discuss the possible mechanism of fistula formation and the results of pathological examination [20-25]; and only two of these reports include detailed pathological images [20, 25]. Therefore, the precise mechanism underlying fistula formation remains to be clarified pathologically.

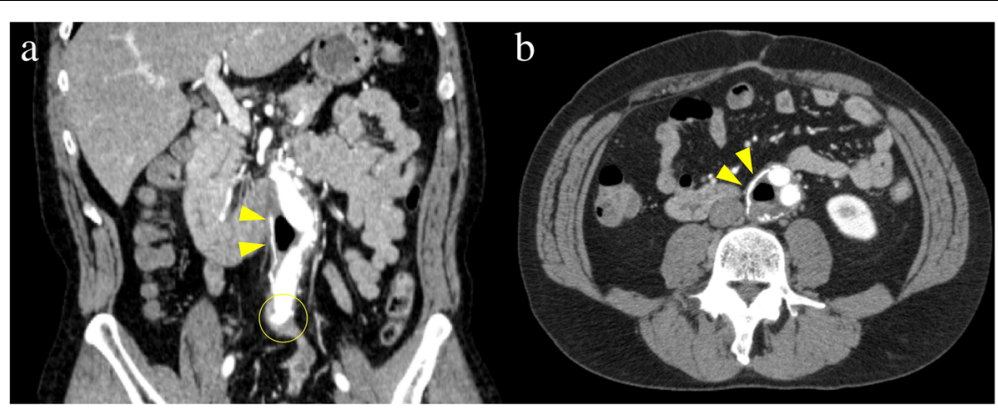

Fig. 1 Contrast-enhanced computer tomography (coronary (a) and axial (b) view) revealed gas within aneurysm sac (yellow arrowhead), and attachment of ileum to anastomosis between left branch of graft and left common iliac artery (yellow circle) 


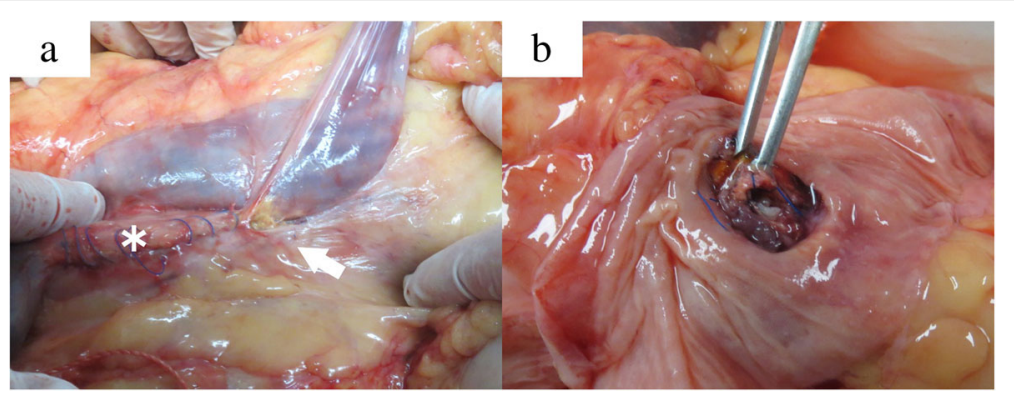

Fig. 2 Image at autopsy. Adhesion of the distal ileum to the anastomosis between the left branch of the graft and the left common iliac artery (arrow), and the postoperative aneurysm sac on the head side (asterisk) (a), with a small hole at the aortic anastomosis in dissected ileum (b)

The present autopsy findings suggested that physical stimuli following postoperative adhesion and attachment between the iliac artery and small bowel had contributed to the formation of the fistula, although chronic infection of the graft could not be excluded completely. Despite fibrillar change in the serous membrane and muscularis propria layer of the intestine, inflammatory cell infiltration was sparse at the edge of the fistula. Moreover, there was no sign of phagocytosis, indicating no destructive infection of the graft. The arterial wall exhibited fibrous thickening, however, possibly due to continuous physical stimulation. These pathological findings and the clinical course suggested that the persistent pulsation of the aorta had physically degraded the attached intestinal wall and aortic membrane, inducing erosion of the bowel tract. Fatal bleeding appears to have occurred when the vulnerable inner membrane of the attached aorta finally ruptured.
In terms of the underlying mechanism of fistula formation, the present findings reaffirm the importance of avoiding adhesion between the intestinal wall and the anastomosis of the graft due to insufficient isolation of the latter [26]. Interposing native tissue between the aorta and the intestinal tract at primary surgery has been reported as effective in preventing SAEF associated with physical stimuli [1]. In the present case, the artery and intestinal tract had adhered tightly at the site of the fistula, even though the artificial graft had been covered with a longitudinally split aneurysmal wall and retroperitoneum during primary surgery. This particular fistula involved both the ileum and the distal suture line of the graft, a relatively rare site for an SAEF. The ileum might have become trapped by adhering to the closing line of the retroperitoneum after primary surgery, resulting in tight contact with the distal anastomosis of the graft. This suggests that keeping a graft isolated from the

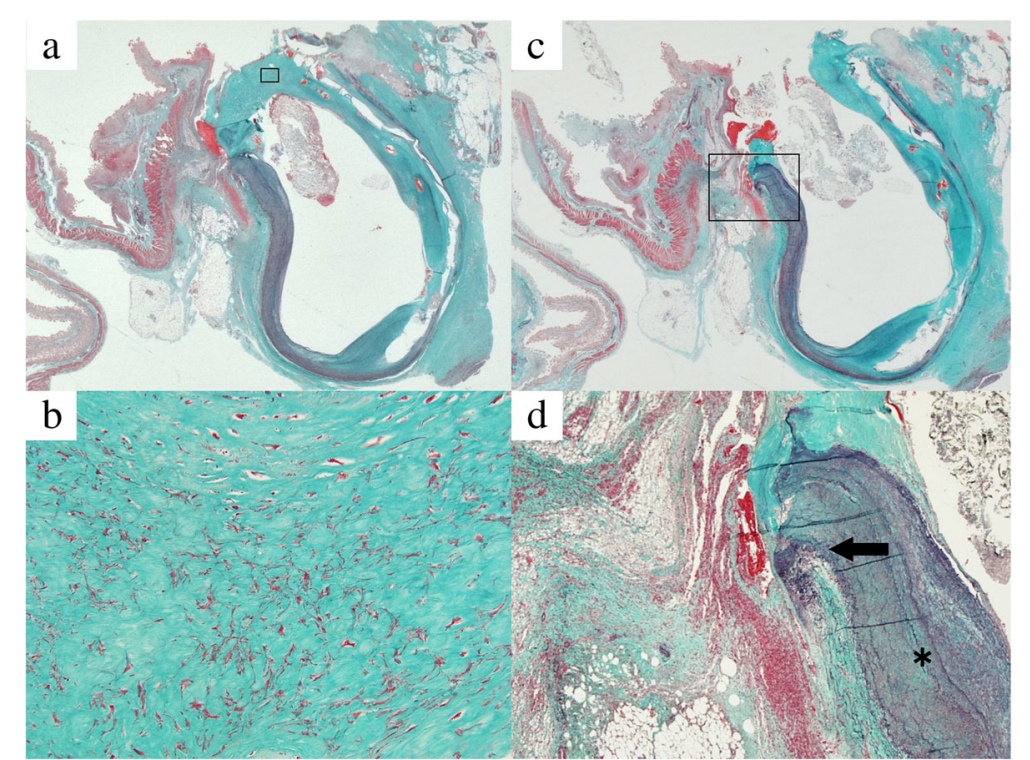

Fig. 3 Histology of left common iliac artery by Elastica van Gieson stain revealed fibrotic and thickened intima of anastomosed artery exposed to intestinal lumen at edge of fistula (a whole, magnification $\times 1$; b square, magnification $\times 400$ ). Histology of fistula revealed firm adhesion (arrow) between serosa of intestinal tract and adventitia of artery (asterisk) (c whole, magnification $\times 1$; $\mathbf{d}$ square, magnification $\times 40$ ) 


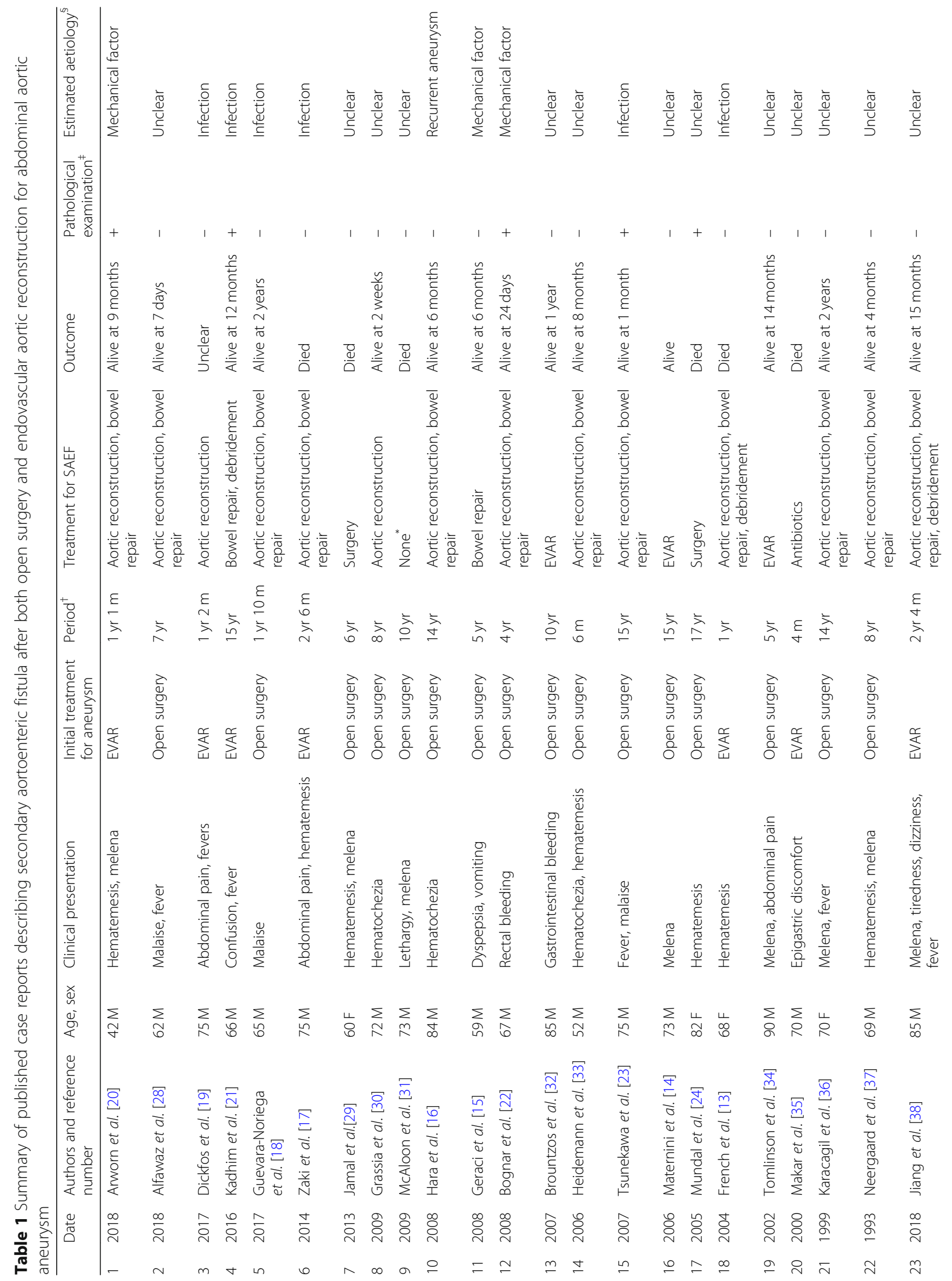




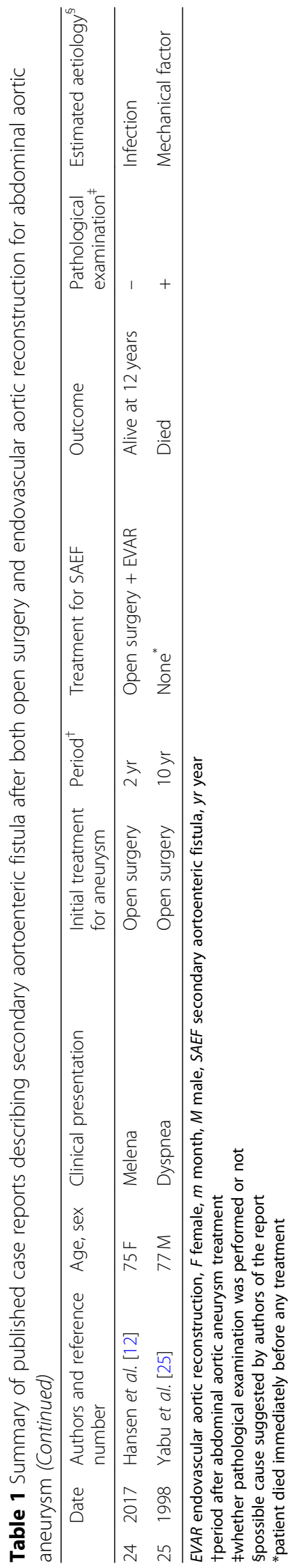


intestinal wall in the usual fashion during surgery may only be effective up to a certain point, and that further adjuvant maneuvering may be necessary to maintain postoperative isolation. Adhesive barriers could be applied to cover the closing line of the retroperitoneum.

Clinically, SAEFs present in a variety of ways, which makes a prompt diagnosis challenging $[3,8]$. Whereas gastrointestinal bleeding occurs in most such cases, sepsis occurs in only approximately half on initial presentation $[5,8,27]$, which is possibly because such symptoms are unlikely if the fistula was formed mainly due to mechanical stimuli. Infection might occur later, however, through contact with intestinal bacteria. Therefore, an SAEF should be suspected in cases of bloody stool or hematemesis after AAA reconstruction, even in the absence of septic symptoms. If an SAEF is the suspected cause of bloody stool, immediate exploratory surgery should be considered to prevent potentially catastrophic developments, even if the general status of the patient is stable.

\section{Conclusions}

This case report described gastrointestinal bleeding due to an SAEF. Physical stimuli were associated with its formation due to adhesion between the aorta and the intestinal wall after AAA reconstruction, indicating the importance of keeping a reconstructed aorta isolated from the intestine. Clinicians should suspect SAEF in patients with bloody stool after aneurysm surgery.

\footnotetext{
Abbreviations

AAA: Abdominal aortic aneurysm; CT: Computed tomography;

SAEF: Secondary aortoenteric fistula
}

\section{Acknowledgements}

The authors would like to thank Professor Jeremy Williams of the Department of International Medical Communications at Tokyo Medical University for his assistance with the writing of this manuscript.

\section{Funding}

No funding was received.

\section{Availability of data and materials}

The datasets generated during the current report are not publicly available due to privacy of information, but are available from the corresponding author on reasonable request.

\section{Authors' contributions for all aspects of the work: all authors. \\ Ethics approval and consent to participate Not applicable.}

Study conception: HS, YN, and MT. Writing: HS and YN. Critical review and revisions: all authors. Final approval of the article: all authors. Accountability

\section{Consent for publication}

Written informed consent was obtained from the patient's next-of-kin for publication of this case report and any accompanying images. A copy of the written consent is available for review by the Editor-in-Chief of this journal.

\section{Competing interests}

The authors declare that they have no competing interests.

\section{Publisher's Note}

Springer Nature remains neutral with regard to jurisdictional claims in published maps and institutional affiliations.

\section{Author details}

'Department of Gastroenterology, Sendai Kousei Hospital, Sendai, Miyagi, Japan. ${ }^{2}$ Department of Internal Medicine, Hirata Central Hospital, Fukushima, Ishikawa, Japan. ${ }^{3}$ Department of Health Informatics, Kyoto University School of Public Health, Kyoto, Kyoto, Japan. ${ }^{4}$ Department of Pathology, Sendai Kousei Hospital, Sendai, Miyagi, Japan. ${ }^{5}$ Sendai Gastrointestinal Endoscopy Clinic, Sendai, Miyagi, Japan. ${ }^{6}$ Department of Surgery, Minamisoma Municipal General Hospital, Minamisoma, Fukushima, Japan. ${ }^{7}$ Department of Public Health, Fukushima Medical University School of Medicine, Fukushima, Fukushima, Japan. ${ }^{8}$ Department of Cardiovascular Surgery, Sendai Kousei Hospital, Sendai, Miyagi, Japan.

Received: 4 October 2018 Accepted: 31 January 2019

Published online: 15 March 2019

\section{References}

1. Wilson WR, Bower TC, Creager MA, Amin-Hanjani S, O'Gara PT, Lockhart PB, Darouiche RO, Ramlawi B, Derdeyn CP, Bolger AF, et al. Vascular Graft Infections, Mycotic Aneurysms, and Endovascular Infections: A Scientific Statement From the American Heart Association. Circulation. 2016;134(20): e412-60.

2. Champion MC, Sullivan S, Coles J, Goldbach M, Watson WC. Aortoenteric fistula. Incidence, presentation recognition, and management. Ann Surg. 1982;195(3):314-7.

3. Hallett JW Jr, Marshall DM, Petterson TM, Gray DT, Bower TC, Cherry KJ Jr, Gloviczki P, Pairolero PC. Graft-related complications after abdominal aortic aneurysm repair: reassurance from a 36-year population-based experience. J Vasc Surg. 1997;25(2):277-84. discussion 285-276

4. Chenu C, Marcheix B, Barcelo C, Rousseau H. Aorto-enteric fistula after endovascular abdominal aortic aneurysm repair: case report and review. Eur J Vasc Endovasc Surg. 2009;37(4):401-6.

5. Malik MU, Ucbilek E, Sherwal AS. Critical gastrointestinal bleed due to secondary aortoenteric fistula. J Community Hosp Intern Med Perspect. 2015;5(6):29677.

6. Gnus J, Ferenc S, Koscielna M, Paprocka-Borowicz M, Dawidczyk P, Dziewiszek M, Witkiewicz W. Secondary Aortoenteric Fistula After Abdominal Aortic Graft Implementation in Our Own Material. Adv Clin Exp Med. 2016;25(6):1265-71

7. Armstrong PA, Back MR, Wilson JS, Shames ML, Johnson BL, Bandyk DF. Improved outcomes in the recent management of secondary aortoenteric fistula. J Vasc Surg. 2005;42(4):660-6.

8. Bergqvist D, Bjorck M. Secondary arterioenteric fistulation-a systematic literature analysis. Eur J Vasc Endovasc Surg. 2009;37(1):31-42.

9. Perdue GD Jr, Smith RB 3rd, Ansley JD, Costantino MJ. Impending aortoenteric hemorrhage: the effect of early recognition on improved outcome. Ann Surg. 1980;192(2):237-43.

10. Takeda Y, Daimon M, Katsumata T, Morita H, and Ishizaka N. Repetitive complications after prosthetic graft for inflammatory aortic aneurysm. SAGE Open Med Case Rep. https://doi.org/10.1177/2050313X13513230.

11. Tagowski M, Vieweg H, Wissgott C, Andresen R. Aortoenteric fistula as a complication of open reconstruction and endovascular repair of abdominal aorta. Radiol Res Pract. 2014;2014:383159.

12. Hansen BA, Amundsen S, Reikvam H, Wendelbo O, Pedersen G. Noncurative surgery for aortoenteric fistula. J Surg Case Rep. 2017;2017(8):rjx153.

13. French JR, Simring DV, Merrett N, Thursby P. Aorto-enteric fistula following endoluminal abdominal aortic aneurysm repair. ANZ J Surg. 2004;74(5):397-9.

14. Maternini M, Tozzi $P$, Vuilleumier $H$, Von Segesser LK. Intra vascular ultra sound: one more tool to diagnose aorto-duodenal fistula. Eur J Vasc Endovasc Surg. 2006;32(5):542-4.

15. Geraci G, Pisello F, Li Volsi F, Facella T, Platia L, Modica G, Sciume C. Secondary aortoduodenal fistula. World J Gastroenterol. 2008;14(3):484-6.

16. Hara H, Shinji A, Mukawa K, Takayama M, Okiyama W, Yamamura N, Oguchi $\mathrm{H}$. Internal iliac artery aneurysm rupture with aorto-enteric fistula after reconstruction of abdominal aortic aneurysm: report of a case. Nihon Shokakibyo Gakkai Zasshi. 2008;105(2):221-7. 
17. Zaki M, Tawfick W, Alawy M, ElKassaby M, Hynes N, Sultan S. Secondary aortoduodenal fistula following endovascular repair of inflammatory abdominal aortic aneurysm due to Streptococcus anginosus infection: A case report and literature review. Int J Surg Case Rep. 2014;5(10):710-3.

18. Guevara-Noriega KA, Velescu A, Zaffalon-Espinal DT, Mateos-Torres E, RoigSantamaria L, Clara-Velasco A. Aorto-bifermoral graft infection due to Candida parapsilosis. An unusual pathogen. Cirugia y Cirujanos. 2017;85(3): 234-9.

19. Dickfos M, Garnham K, Jenkins J. Salmonella typhimurium Infected Abdominal Aortic Aneurysm Endovascular Repair with Secondary Aortoenteric Fistula Formation. S Afr J Surg. 2017;55(3):77.

20. Arworn S, Orrapin S, Chakrabandhu B, Reanpang T, Settakorn J, Laohapensang K. Aorto-enteric Fistula After Endovascular Abdominal Aortic Aneurysm Repair for Behcet's Disease Patient: A Case Report. EJVES Short Rep. 2018;39:54-7.

21. Kadhim MMK, Rasmussen JBG, Eiberg JP. Aorto-enteric Fistula 15 Years After Uncomplicated Endovascular Aortic Repair with Unforeseen Onset of Endocarditis. EJVES Short Rep. 2016;31(2405-6553 (Print)):16-8.

22. Bognar G, Sugar I, Sipos P, Ledniczky G, Laczko A, Ondrejka P. Secondary iliac-enteric fistula to the sigmoid colon complicated with entero-graftocutaneous fistula. Case Rep Gastroenterol. 2008;2(1):138-43.

23. Tsunekawa T, Ogino H, Minatoya K, Matsuda H, Sasaki H, Fukuchi K. Masked prosthetic graft to sigmoid colon fistula diagnosed by 18fluorodeoxyglucose positron emission tomography. Eur J Vasc Endovasc Surg. 2007;33(2):187-9.

24. Mundal L, Ignjatovic D, Vage V, Asmussen I, Sund S. A woman with hemorrhagic shock. Tidsskr Nor Laegeforen. 2005;125(13):1833-4.

25. Yabu M, Himeno S, Kanayama Y, Furubayashi T, Kiriyama K, Nagasawa Y, Takakura R, Katata T, Iwao N, Orino A. Secondary aortoduodenal fistula complicating aortic grafting, as a cause of intermittent chronic intestinal bleeding. Intern Med. 1998;37(1):47-50.

26. Connolly JE, Kwaan JH, McCart PM, Brownell DA, Levine EF. Aortoenteric fistula. Ann Surg. 1981;194(4):402-12.

27. Biro G, Szabo G, Fehervari M, Munch Z, Szeberin Z, Acsady G. Late outcome following open surgical management of secondary aortoenteric fistula. Langenbeck's Arch Surg. 2011;396(8):1221-9.

28. Alfawaz A, Tashiro J, Sleeman D, Jones K, Rey J. Total retroperitoneal approach to aortic reconstruction: A novel technique for aorto-enteric fistulae and graft infections. SAGE Open Med Case Rep. 2018;6(2050-313X (Print)) https://doi.org/10.1177/2050313X18760467.

29. Jamal K, Shaunak S, Kalsi S, Nehra D. Secondary aorto-enteric fistula presenting over a 2-month period with recurrent gastrointestinal bleeding. BMJ Case Rep. 2013;2013 https://doi.org/10.1136/bcr-2012-008070.

30. Grassia R, Staiano T, liritano E, Bianchi G, Dizioli P, Baratta V, Buffoli F. Gastrointestinal hemorrhage caused by secondary aorto-duodenal fistula: a case report. Eur Rev Med Pharmacol Sci. 2009;13(2):147-50.

31. McAloon CJ, Leong WB, Garg R, Narendran P. Secondary aorto-enteric fistula: a case report and review of literature. BMJ Case Rep. 2009;2009(1757790X (Electronic)) https://doi.org/10.1136/bcr.08.2008.0721.

32. Brountzos EN, Vasdekis S, Kostopanagiotou G, Danias N, Alexopoulou E, Petropoulou K, Gouliamos A, Perros G. Endovascular treatment of a bleeding secondary aorto-enteric fistula. A case report with 1-year followup. Cardiovasc Intervent Radiol. 2007;30(5):1037-41.

33. Heidemann J, Domagk D, Wessling J, Domschke W, Kucharzik TF. Recurrent obscure gastrointestinal bleeding caused by aorto-enteric fistula. Z Gastroenterol. 2006:44(9):981-4.

34. Tomlinson MA, Gold B, Thomas MH, Browning NG. Endovascular stent graft repair of a recurrent aorto-enteric fistula. Eur J Vasc Endovasc Surg. 2002; 24(5):459-61.

35. Makar R, Reid J, Pherwani AD, Johnston LC, Hannon RJ, Lee B, Soong CV. Aorto-enteric fistula following endovascular repair of abdominal aortic aneurysm. Eur J Vasc Endovasc Surg. 2000;20(6):588-90.

36. Karacagil $\mathrm{S}$, Thelin $\mathrm{S}$, Grewal P, Bergqvist D. Type IV thoraco-abdominal aortic aneurysm complicated by an aorto-enteric fistula due to previous infrarenal aortic graft. Eur J Vasc Endovasc Surg. 1999;17(3):268-70.

37. Neergaard K, Mantoni M, Andersen L. Aorto-enteric fistula: unusual CT appearance. Eur J Radiol. 1993;16(3):213-4.

38. Jiang C, Chen X, Li J, Li H. A case report of successful treatment of secondary aortoenteric fistula complicated with gastrointestinal bleeding and retroperitoneal abscess in an elderly patient. Medicine. 2018;97(24): e11055.

\section{Ready to submit your research? Choose BMC and benefit from:}

- fast, convenient online submission

- thorough peer review by experienced researchers in your field

- rapid publication on acceptance

- support for research data, including large and complex data types

- gold Open Access which fosters wider collaboration and increased citations

- maximum visibility for your research: over $100 \mathrm{M}$ website views per year

At BMC, research is always in progress.

Learn more biomedcentral.com/submissions 